\title{
Ketoacidosis associated with low-carbohydrate diet in a non-diabetic lactating woman: a case report
}

\author{
Louise von Geijer ${ }^{1}$ and Magnus Ekelund ${ }^{2^{*}}$
}

\begin{abstract}
Introduction: Non-diabetic ketoacidosis is a rare condition which can be caused by starvation. Lack of glucose can force the body into ketogenesis causing a metabolic acidosis. As previously reported in the literature, ketoacidosis might, on rare occasions, be caused by a diet with low carbohydrate content. However, to the best of our knowledge this is the first reported case in the literature of ketoacidosis, in a non-diabetic patient, associated with a combination of low carbohydrate, high fat diet and lactation.
\end{abstract}

Case presentation: A healthy non-diabetic, 32-year old white woman started a low carbohydrate, high fat diet when she was breastfeeding her son of 10 months of age. After 10 days she was admitted to our hospital with nausea and vomiting and a serum pH of 7.20 and base excess of -19 . Clinical signs and blood samples were compatible with ketoacidosis. She was given fluids intravenously and insulin. No anamnestic or clinical signs of diabetes were found. She recovered quickly and was discharged 3 days later.

Conclusions: Ketogenic diets like low carbohydrate, high fat may induce ketoacidosis. Lactation might further aggravate the condition and can perhaps even be the trigger into ketoacidosis. Health services should be aware of the risks associated with ketogenic diets, and be able to recognize this serious condition when it is presented.

Keywords: Diet, Ketoacidosis, Lactation, LCHF diet, Low-carbohydrate

\section{Introduction}

Metabolic acidosis is a potentially life-threatening condition that can occur due to ketoacidosis caused by diabetes mellitus, starvation, alcohol ingestion or lactate acidosis, renal failure or ingestion of substances (that is, methanol, ethylene glycol or salicylate). Anamnesis, clinical signs and blood samples are used to determine the origin of the acidosis.

Ketosis during lactation is a well-known phenomenon in lactating cattle and is well described in veterinary literature [1]. During lactation the metabolic demand is higher in the lactating female due to milk production and secretion than in the non-lactating female [2]. The condition is rare since it is normally compensated for by increased dietary intake. Ketoacidosis not associated with

\footnotetext{
* Correspondence: magnus.ekelund@med.lu.se

${ }^{2}$ Department of Internal Medicine, Helsingborg Hospital, SE-251 87

Helsingborg, Sweden

Full list of author information is available at the end of the article
}

lactation has, in previous case reports, been reported to be caused by a diet with low carbohydrate content $[3,4]$.

When the body's glycogen storages are depleted, as under starvation, the brain's demand for energy is met by gluconeogenesis and, later, due to low insulin levels, mobilization of free fatty acids into ketone bodies [5]; the little amount of glucose made through gluconeogenesis is used for galactopoiesis to the offspring.

Low carbohydrate diets became popular in the USA during the 1960s and peaked around year 2000, spurred by books written by Dr Stillman [6] and Dr Atkins [7]. In Sweden the low carbohydrate high fat (LCHF) diet was introduced in 2005 by a Swedish general practitioner and interest was generated when the creator started a blog, which criticized the traditional dietary advice for patients with diabetes [8]. Since then the diet has become increasingly popular.

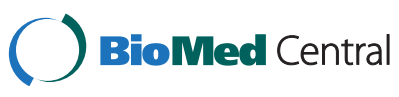

(c) 2015 von Geijer and Ekelund. Open Access This article is distributed under the terms of the Creative Commons Attribution 4.0 International License (http://creativecommons.org/licenses/by/4.0/), which permits unrestricted use, distribution, and reproduction in any medium, provided you give appropriate credit to the original author(s) and the source, provide a link to the Creative Commons license, and indicate if changes were made. The Creative Commons Public Domain Dedication waiver (http://creativecommons.org/publicdomain/zero/1.0/) applies to the data made available in this article, unless otherwise stated. 


\section{Case presentation}

A 32-year-old white woman presented to our county hospital with a history of nausea, vomiting, heart palpitations, trembling and extremity spasms. She had started a strict LCHF diet, with an estimated carbohydrate intake of less than $20 \mathrm{~g}$ per day, 10 days before admittance, lost 4 kilograms and had felt growing malaise. She was breastfeeding her son of 10 months of age. She continuously denied any alcohol or drug intake. She had a past medical history of hypothyreosis and had a family history of high blood pressure but not for diabetes. She took acetaminophen occasionally but no other medications.

The initial examination in the emergency department revealed an unaffected woman with respiratory rate of 12 breaths per minute, oxygen saturation $96 \%$ on room air, body temperature $36.3^{\circ} \mathrm{C}$, pulse 102 beats per minute and blood pressure of $110 / 80 \mathrm{mmHg}$. Nothing abnormal was revealed on examination of her heart, lungs, abdomen and thyroid gland.

An arterial blood gas was taken. It revealed $\mathrm{pH} 7.20$, base excess $(\mathrm{BE})-19$, partial pressure of carbon dioxide $\left(\mathrm{pCO}_{2}\right) 2.8 \mathrm{kPa}$, glucose $3.8 \mathrm{mmol} / \mathrm{l}$ and lactate $1.0 \mathrm{mmol} / \mathrm{l}$. Her blood ketones were $7.1 \mathrm{mmol} / \mathrm{l}$ (reference 0 to $0.5 \mathrm{mmol} / \mathrm{l})$. No genetic testing of any kind was performed.

The primary diagnosis was thought to be ketoacidosis due to starvation induced by the LCHF diet but blood samples for s-paracetamol, s-salicylate, s-ethanol, s-methanol, s-ethylene glycol, kidney function, diabetic autoantibodies, plasma cortisol (p-cortisol) and tests for thyroid function were added. She was admitted to our medical ward, given an intramuscular vitamin B injection and started on a $10 \%$ glucose infusion. In total $3 \mathrm{~L}$ of glucose were infused, with an infusion rate of $125 \mathrm{~mL} /$ hour, during 48 hours.

The following day, after glucose infusion and small doses of human insulin administered intravenously and insulin aspart subcutaneously, her acidosis was reversed. In total 4 units of insulin were administered during 24 hours. She was discharged, fully recovered, after 3 days and follow-up was performed after 1 month.

Diabetes mellitus was excluded by normal blood glucose and C-peptide, glycated hemoglobin (HbA1c) $37 \mathrm{mmol} / \mathrm{mol}$ and negative autoantibodies: islet antigen number 2 (IA2) $<15 \mathrm{kE} / \mathrm{L}$, reference $<15$ and glutamic acid decarboxylase (GAD) $<5 \mathrm{kE} / \mathrm{L}$, reference $<5$. No drugs could be detected in her blood and her kidney function was normal (S-creatinine $67 \mu \mathrm{mol} / \mathrm{L}$, reference 45 to 90). The day after admittance her thyroid-stimulating hormone (TSH) was normal (2.5 mIE/L, reference 0.4 to 3.7$)$ but her triiodothyronine $\left(\mathrm{T}_{3}\right)$ and thyroxine $\left(\mathrm{T}_{4}\right)$ were low: $\mathrm{T}_{3} 2.6 \mathrm{pmol} / \mathrm{L}$, reference 3.6 to 6.3 and $\mathrm{T}_{4} 11 \mathrm{pmol} / \mathrm{L}$, reference 12 to $22 \mathrm{pmol} / \mathrm{L}$. However, on the follow up 1 month later, her thyroid tests had normalized and thyroid peroxidase (TPO) antibodies were negative. Her p-cortisol was normal, $674 \mathrm{nmol} / \mathrm{L}$, in the morning (reference 200 to 800 ) as well as adrenocorticotropic hormone (ACTH). The lack of other possible explanations supported the primary diagnosis: ketoacidosis due to starvation.

\section{Discussion}

In our case, a healthy lactating woman presented with ketoacidosis despite lack of a diabetes diagnosis. Ketoacidosis might on rare occasions be caused by a diet with low carbohydrate content. However, to the best of our knowledge this is the first reported case in the literature of ketoacidosis in a non-diabetic patient, associated with a combination of low carbohydrate, high fat diet and lactation. In previous cases of ketoacidosis, in lactating non-diabetic women as well as in other non-diabetic patients, physiological stressors such as fasting, infections, lactating twins and recently even bariatric surgery have been considered to be the push factor into ketoacidosis [9-14]. In our case the stressor seemed to be the LCHF diet in combination with lactation and its high demand of substrate to produce milk.

New diets are popular and with our modern communication, through Internet and blogs, the information spreads fast and is easily accessible. Authors on the Internet might be people supporting the diet or advertisers with commercial interests. It is a great challenge for medical services to be updated and to give proper information to our community.

It is important to make patients aware of the fact that active weight loss should not be undertaken during breast feeding, due to the high demand of substrate to produce milk and since the individual ability to utilize ketones usually is not known.

\section{Conclusions}

A lactating woman has a high demand of substrate to produce milk. A LCHF diet limits the amount of substrate and results in a negative energy balance. This kind of diet should thus be avoided during lactation.

Our case shows that medical services should be aware of the fact that a strict LCHF diet often leads to ketosis and in rare cases even into ketoacidosis which is a dangerous condition that must be immediately diagnosed and treated in order to reduce morbidity.

\section{Consent}

Written informed consent was obtained from the patient for publication of this case report. A copy of the written consent is available for review by the Editor-in-Chief of this journal.

\section{Abbreviations}

LCHF: Low carbohydrate high fat; p-cortisol: Plasma cortisol;

$\mathrm{T}_{3}$ : Triiodothyronine; $\mathrm{T}_{4}$ : Thyroxine. 


\section{Competing interests}

The authors declare that they have no competing interests.

\section{Authors' contributions}

Both authors have been involved in all phases of the preparation of this manuscript. Both authors have read and approved the final version of this manuscript.

\section{Acknowledgements}

We would like to thank our patient who has given us consent to publish her medical data.

\section{Author details}

${ }^{1}$ Department of Gynaecology \& Obstetrics, Helsingborg Hospital, SE-251 87 Helsingborg, Sweden. ${ }^{2}$ Department of Internal Medicine, Helsingborg Hospital, SE-251 87 Helsingborg, Sweden.

Received: 11 February 2015 Accepted: 15 September 2015

Published online: 01 October 2015

\section{References}

1. Holtenius P, Holtenius K. New aspects of ketone bodies in energy metabolism of dairy cows: a review. J Vet Med. 1996;43:579-87.

2. Institute of Medicine. Standing committee on the scientific evaluation of dietary reference intakes. Washington DC: National Academy Press; 2005.

3. Shah P, Isley WL. Ketoacidosis during a low-carbohydrate diet. N Engl J Med. 2006;354:1.

4. Chen TY, Smith W, Rosenstock JL. A life-threatening complication of Atkins diet. Lancet. 2006;367:958.

5. Ferrier DR. Biochemistry. sixthth ed. Baltimore: Lippincott's Illustrated Reviews; 2013

6. Stillman IM. The doctor's quick weight loss diet. New York: Dell publishing; 1967.

7. Atkins RC. Dr. Atkins diet revolution: the high calorie way to stay thin forever. New York: David McKay; 1972.

8. Swedish Council on Health Technology Assessment. SBU rapport 2010 Sweden: Mat vid Diabetes; 2010.

9. Szulewski A, Howes D, Ross Morton A. A severe case of iatrogenic lactation ketoacidosis. BMJ Case Reports. 2012. doi:10.1136/bcr.12.2011.5409.

10. Chernow B, Finton C, Rainey TG, O'Brian J. 'Bovine ketosis' in a nondiabetic postpartum woman. Diabetes Care. 1982;5(1):47-9.

11. Sandhu HS, Michelis MF, DeVita MV. A case of bovine ketoacidosis in a lactating woman. NDT Plus. 2009;2:278-9.

12. Heffner AC, Johnson DP. A case of lactation "bovine" ketoacidosis. J Emerg Med. 2008;35:38.

13. Altus P, Hickman JW. Severe spontaneous 'bovine' ketoacidosis in a lactating woman. J Indiana State Med Assoc. 1983;76:392-3.

14. Monnier D, Goulenok T, Allary J, Zarrouk V, Fantin B. Starvation ketosis in a breastfeeding woman. Rev Med Interne. 2015; Epub Apr 22.

\section{Submit your next manuscript to BioMed Central and take full advantage of:}

- Convenient online submission

- Thorough peer review

- No space constraints or color figure charges

- Immediate publication on acceptance

- Inclusion in PubMed, CAS, Scopus and Google Scholar

- Research which is freely available for redistribution

Submit your manuscript at www.biomedcentral.com/submit 